\title{
REVIEW OF STANDARDS AND STANDARDISATION ACTIVITIES
}

\author{
Rolf Lindner \\ ComputerScience Department, TU Darmstadt, Germany
}

\begin{abstract}
An short review of standards and standardisation activities in the field of employing information and communication technology for learning, education, and training is provided.
\end{abstract}

Key words: Learning; Education; Training; Information; Communication; Technology; Standard; Specification

\section{INTRODUCTION}

Today's electronic design means first of all the design of highly integrated electronic circuits. This design is supported through the use of specific descriptive languages (like VHDL - Very High-level Design Language), tools for VLSI synthesis (like the Synopsis software), and simulators (like HSPICE). Considering Learning, Education and Training (LET) in this field will also include basic knowledge and skills like electrical engineering, computer science, and mathematics. In this panel, the state-ofthe-art of education in these fields will be discussed in the context of how they can be further supported and advanced by the use of Information and Communication Technology (ICT), and how learning technology standards can be of help here. 


\section{EXISTING AND EXPECTED LT STANDARDS}

There is a small number of standards which have been developed particularly for the LET field. Below, those existing standards and standards projects are listed and briefly described which are of obvious importance for the support of LET applications.

\subsection{Computer Managed Instruction}

The most popular approach for ICT LET support is found in the field of Computer Managed Instruction (CMI). These activities can be traced back to the time long before the advent of the World Wide Web and powerful computers like they are at hand to everybody today.

The basic idea of CMI is using computers as multiplicators for human topical and educational expertise. This is done by transforming the human expertise into diverse formats that can be put into operation by machines and that are able to communicate with humans through the help of machines.

Huge amounts of material of this kind have been produced, spending hours and hours of experts' work. Cost-effectiveness is sought through all kinds of multiple use and adaptation to multiple purposes. Interoperability between operational platforms (so-called Learning Management Systems) and domains of learning material is essential for efficiency in this field.

The Content Communication (IEEE 1484.11.x) activities of the IEEE LTSC $^{1}$ WG11 comprise a set of correlated standards for the CMI field. This set will contain at least standards for:

- Data Model for Content to Learning Management System Communication (IEEE P1484.11.1)

- ECMAScript Application Programming Interface for Content to Runtime Services Communication (IEEE Std 1484.11.2 ${ }^{\mathrm{TM}}-2003$ )

- XML Binding for Content to Learning Management System Communication

These standards specify the rules how learning material interacts (communicates) with the operational software that provides the material objects. They concern the basic level of interoperability and are therefore of extremely high importance.

\subsection{Learning Resource Metadata}

Learning Resource Metadata (LRM) comprise semantical, technical and organisational information on learning resources (such as the addressed subject and method of systematic identification, the intended educational use, the technical format and object size, the intellectual property and usage 
conditions, etc). LRM provide categories and values for search attributes and all the same contextual information related to the use of the resources (e.g. a fraction of the context associated with a learning progress report).

There exists one international standard in this field that arose from the Learning Objects Metadata (LOM - IEEE 1484.12.x) activities of the IEEE LTSC WG12 and has its sources in several previous European initiatives. It comprises a set of correlated standards that will contain at least standards for:

- Learning Object Metadata (IEEE Std 1484.12.1 $1^{\mathrm{TM}}-2002$ )

- ISO/IEC 11404 binding for Learning Object Metadata data model (IEEE P1484.12.2)

- XML binding for Learning Object Metadata data model (IEEE P1484.12.3)

- Resource Description Framework (RDF) binding for Learning Object Metadata data model (IEEE P1484.12.4)

Learning resource metadata can be seen as the "conceptional language" of the machines that are engaged to cooperate with humans. LRM are understood by humans and they can be evaluated and processed by machines.

\subsection{Participant Information}

The term participant denotes all kinds of actors in an application environment. In the LET field, typical participants are individuals or groupings of learners, tutors, teachers and authors, but as well software agents that may act as technically implemented substitutes (such as an automatic helpdesk that may substitute a human helper).

Participant information is of the same information category as LRM is. The term "metadata" is, however, not used here.

The only already existing international standard in this group is providing just the data type for a login-string:

- ISO/IEC IS 24703: $:^{2}$ Information technology - Participant identifiers. The purpose of this Standard is to define the datatype of an identifier for the purposes of identifying participants in learning, education and training. Participants may be users, teachers, agents, groups, organisations, institutions, etc.

This standard was sufficiently simple for achieving international consensus within a short period of time. This is not the case with other standards projects in the field of Information Technology (IT) for LET (ITLET):

- ISO/IEC project 19786: ITLET -- Participant accommodation information 
- Proposal ITLET -- Description of language capabilities

- ISO/IEC project 19787: ITLET -- Participant performance information

- ISO/IEC project 24726 ITLET -- Data Model for Specifying Performance Metrics

Accommodation information is provided for the purpose of supporting the adaptation of services to particular preferences, capabilities, disabilities, etc. of participants (e.g.: preferring graphical representation of information for those humans who are particularly gifted to make use of this kind of representation). In this context, the description of language capabilities is part of this approach. There are other initiatives that are important in this field like the recommendations of the World Wide Web Consortium (W3C) ${ }^{3}$ related to Web-based material and user interfaces.

The slowness of achieving consensus on information models (and data models) in the field of participant information results from the complexity of these attributes and their structuring inside the information models. Plans for handling these attributes in smaller, coherent groupings reflects the attempt of digesting these issues in smaller bits.

Performance information is provided for the purpose of supporting the adaptation of services to the expectable knowledge, expertise, skill, talent, etc. of participants (e.g. filling particular knowledge gaps, avoiding repetition of information that is apparently known). There are many initiatives doing specification work in this field. As Learning Resource Metadata also address competency (that might arise from making use of a learning resource) it is evident that competency specification is important for both, LRM and Participant Information.

The project on a data model for specifying performance metrics is another attempt of breaking complex information models into fractions, to speed up harmonisation processes, and to allow multiple use of the fractions in diverse standards.

\section{$2.4 \quad$ Conceptual Frameworks}

Supporting LET by ICT is an issue that is controversially discussed in and across the diverse disciplines that are involved. Educators are suspicious of technically oriented experts and tend to accuse them of being ignorant regarding educational facts and findings. Technologists are suspicious of educationally oriented experts and tend to accuse them of having no ideas what technology might provide them and how this is related to cost and values added. Conceptual frameworks contribute to this discussion and aim at providing conceptual models and terminology that help the experts of different disciplines to articulate themselves and develop a common understanding of the involved educational and technical phenomena. 
The only international standard existing in this field is the IEEE Standard for Learning Technology-Learning Technology Systems Architecture (LTSA) (IEEE Std 1484.1TM-2003). This standard focuses mainly on the delivery process of CMI-like educational services. Educators, facing the technically oriented terminology of this standard, do hard to understand its very high abstraction level and are not really willing to accept it and to make intelligent use of it.

Vocabulary and terminology work might well be seen as central contributors to conceptual work. Descriptive formats are planned for communicating the potential of learning environments and their components to all involved stakeholders as well as specifying approaches for quality assurance and management. See e.g.:

- ISO/IEC 19796: ITLET -- Quality Management, Assurance and Metrics

\section{APPLICABLE SPECIFICATIONS}

Important specifications exist in several further important fields that still need time to enter international standardisation. The following list can only indicate the multitude of standards expected in medium or long terms:

- Education modeling initiatives. These initiatives aim at reflecting educational expertise and experience by specifying rules for organising educational processes and providing appropriate support or orientation where this is advantageous. This may include the provision and operation of any kinds of resources and the set up of appropriate infrastructures for handling them.

Typical representatives of such initiatives are the $\mathrm{IMS}^{4}$ Manifests like Simple Sequencing or the IMS Learning Design (derived from a European Educational Modeling Language initiative).

- Harmonisation initiatives for particular kinds of learning material. A typical representative is the IMS Question \& Test Interoperability Specification.

- Initiatives for aggregating resources for delivery purposes. The archetype of such initiatives is the AICC $^{5}$ Content Packaging, now available as an IMS specification. The Content Aggregation Model in the SCORM specifications is in this group as well as diverse Digital Repositories projects that contribute to these initiatives.

It is not at all possible to be exhaustive here and to list all kinds of initiatives that currently exist and are planned. 


\section{APPLICABLE INTEGRATIONS}

The value of standards is implied by their use. Making efforts of bringing standards into action is of highest importance. There are many regional, national and international activities that do work of this kind and that cannot all be listed here. The currently most prominent initiative of this kind is the $\mathrm{ADLs}^{6}$ Sharable Content Object Reference Model (SCORM) initiative that currently focuses on the CMI kinds of LET applications.

\subsection{SCORM - Sharable Content Object Reference Model}

In a previous version (version 1.3), SCORM is denoted to be an "Application Profile". This denotation comes really near to what SCORM represents. The SCORM initiative provides a basic application suite for a community of developers, integrates the most important and recent standards, makes use of prominent specifications that are required for the overall operation, and provides a SCORM-specific, experimental runtime system and very helpful documentation.

The standards, projected standards, and specifications that are integrated into SCORM have been introduced above and are:

- IEEE Data Model For Content Object Communication

- IEEE ECMAScript Application Programming Interface for Content to Runtime Services Communication

- IEEE Learning Object Metadata (LOM)

- IEEE Extensible Markup Language (XML) Schema Binding for Learning Object Metadata Data Model

- IMS Content Packaging

- IMS Simple Sequencing

The main advantage of the SCORM initiative (and of further initiatives of this kind) over individual research and development projects is that of deploying the LT standards by building communities of practice.

\section{SUMMARY}

Harmonisation in LET means building common agreement on how to make use of ICT support for these applications. This is done in order to enable multiple and modifying use of the results from distributed efforts and thus mark down the cost and increase the quality of this support. Achieving 
this harmonization without causing unacceptable implications to LET applications is the challenge to be met in standardisation.

\section{REFERENCES}

1. IEEE Learning Technology Standards Committee (LTSC), http://tsc.ieee.org/

2. ISO/IEC JTC1 SC36 Information Technology for Learning, Education, and Training, http://jtc1sc36.org/

3. World Wide Web Consortium (W3C), http://www.w3.org/

4. IMS Global Learning Consortium, http://www.imsproject.org/

5. Aviation Industry CBT Committee, http://aicc.org/

6. Advanced Distributed Learning (ADL) Initiative, http://www.adlnet.org/ 